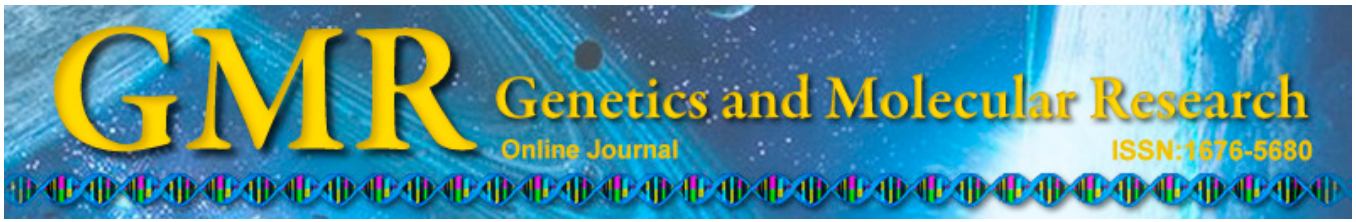

\title{
Isolation, partial characterization, and cloning of an extracellular chitinase from the entomopathogenic fungus Verticillium lecanii
}

\author{
G. Yu' ${ }^{1}$ L.Q. Xie', J.T. Li ${ }^{1}$, X.H. Sun ${ }^{1}$, H. Zhang ${ }^{2}$, Q. Du ${ }^{3}$, Q.Y. Li ${ }^{3}$, \\ S.H. Zhang ${ }^{1}$ and H.Y. Pan ${ }^{1}$ \\ ${ }^{1}$ College of Plant Science, Jilin University, Changchun, China \\ ${ }^{2}$ College of Resource and Environment, Jilin Agricultural University, \\ Changchun, Jilin, China \\ ${ }^{3}$ Jilin Academy of Agricultural Science, Changchun, China \\ Corresponding author: H.Y. Pan \\ E-mail: panhongyu@jlu.edu.cn
}

Genet. Mol. Res. 14 (1): 2275-2289 (2015)

Received March 24, 2014

Accepted September 23, 2014

Published March 27, 2015

DOI http://dx.doi.org/10.4238/2015.March.27.13

\begin{abstract}
The entomopathogenic fungus Verticillium lecanii is a well-known biocontrol agent of fungal phytopathogens, as well as insect pests. A 42-kDa chitinase belonging to family 18 of the glycosyl hydrolases was isolated and partially characterized. Chitinase was purified using successive column chromatography on phenyl-sepharose, DEAE-sepharose, and CM-sepharose. The enzyme showed the highest activity at $40^{\circ} \mathrm{C}$ and $\mathrm{pH} 4.6$. Enzyme activity was strongly activated in the presence of $\mathrm{Mg}^{2+}$. The purified enzyme showed inhibitory activity of spore germination against several plant pathogens, particularly Fusarium moniliforme. The genomic DNA and cDNA sequences were resolved by polymerase chain reaction amplification and sequencing. Protein modeling and comparative investigation of different chitinase amino acids showed that chitinases are conserved in parasitic fungi.
\end{abstract}

Key words: Acidic extracellular chitinase; Inhibitory effect; Protein modeling; Verticillium lecanii 


\section{INTRODUCTION}

Biological control agents are regarded as alternatives to conventional synthetic chemicals, which are known to have negative effects on the environment and non-target organisms, including animals and humans (Harman et al., 1993). However, the major commercial biopesticides have been limited by their lack of efficacy. Many efforts have been made to isolate highperformance pesticidal strains or novel compounds derived from such organisms for use in biological control (Prasanna et al., 2013). The versatile fungus Verticillium lecanii is one of the most promising natural parasites, as it shows tremendous potential as a pest biological control agent against numerous insects, including Coleoptera, Orthoptera, Homoptera, and Lepidoptera (Xu et al., 2011), as well as numerous phytopathogenic fungi, including Sphaerotheca macularis, Puccinia coronata, Penicillium digitatum, Pythium ultimum, and Fusarium moniliforme (Benhamou and Brodeur, 2000, 2001; Miller et al., 2004; Yu et al., 2012). In several phytopathogenic fungal species, $V$. lecanii may induce host defense reactions without showing the pathogenicity phenotype (Benhamou and Brodeur, 2000). Chitin is one of the highest $\beta-1,4-N$ acetyl-D-glucosamine-containing units in nature after cellulose. This molecule provides architectural reinforcement of biological structures, such as insect exoskeletons, crustacean shells, higher fungal cell walls, and other biological matrices involved in protection and self-defense (Hammami et al., 2013). Chitin is also a well-known pathogen-associated molecular pattern that elicits plant immunity. Identified chitin receptors include OsCEBiP in rice and AtCERK1 in the model experimental plant Arabidopsis, both containing an extracellular lysine motif domain that is widely distributed for $N$-acetyl-D-glucosamine recognition, which is required for chitin-triggered immunity (Liu et al., 2012). In addition, this polysaccharide is a main target molecule of biological agents that may secrete chitinolytic enzymes, such as several bacteria, actinomycetes, fungi, higher plants, and animals ( $\mathrm{Li}, 2006)$. Chitinases in fungi play important physiological and ecological roles in defense mechanisms in response to pathogens and abiotic stress, and are also involved in nutrition and pathogenesis. Fungal pathogenesis is a complex process that includes adherence, penetration, and digestion and requires the production of hydrolytic enzymes that penetrate the chitinous cell wall and cuticle, an extremely thick barrier preventing the entry of most fungal pathogens and insects (Li et al., 2004). Chitinases (EC 3.2.1.1.4) are major extracellular-degrading enzymes responsible for the random hydrolysis of internal links of the chitin chain to small-molecule nutrients, which are required during fungus penetration into the insect cuticle or fungal cell wall (Rocha-Pino et al., 2011). In addition, chitinases in plants are important enzymes of protective approaches targeting fungal pathogens, since chitinases in plants can degrade chitin in the fungi cell wall. Chitinases are widely employed in in laboratory and field experiments, such as for the biological control of fungal pathogens, oligosaccharide and $N$-acetyl-D-glucosamine preparations, and protoplast preparation for filamentous fungi. Therefore, chitinases have recently gained attention worldwide for their potential practical uses (Sahai and Manocha, 1993).

Based on the similarity of amino acid sequences, chitinases from various organisms have been grouped into Family 18 and Family 19 of the glycosyl hydrolases, and all fungal chitinases identified to date belong to Family 18 (Henrissat and Bairoch, 1993). In recent years, studies of fungal chitinases have demonstrated progress in gene isolation, functional characterization, and research on chitinase as alternative biocontrol compounds. Purification and characterization of chitinases from mycoparasitic fungi have also been reported, such as from Aphanocladium album, Nomuraea rileyi, Gliocladium virens, and Fusarium 
chlamydosporum (Li, 2006). A chitinase gene, Pcchi44, from Pochonia chlamydosporia was characterized as a virulence factor in infection against nematodes (Mi et al., 2010), while the Lecanicillium psalliotae chitinase gene Lpchil was found to play a role in the biocontrol of the root-knot nematode Meloidogyne incognita (Gan et al., 2007). Chitinases in the Trichoderma genus have been investigated intensively and extensively for their widespread application in field biocontrol; for instance, chitinases in Trichoderma harzianum, Trichoderma virens, Trichoderma atroviride, and Trichoderma asperellum have been isolated and biochemically characterized (Ihrmark et al., 2010). Recently, a purified chitinase from Stenotrophomonas maltophilia, a bacterium that is antagonistic toward fungal phytopathogens, was shown to inhibit the growth of fungal phytopathogens belonging to the genera Fusarium, Rhizoctonia, and Alternaria (Jankiewicz et al., 2012). A purified chilO8 from Bacillus cereus exhibited activity against Botrytis cinerea in an in vivo assay (Hammami et al., 2013). A genetic transformation and expression system for temporal and spatial regulation of gene expression has been established in $V$. lecanii to facilitate the study of gene function in vivo. Development of $V$. lecanii as a biopesticide requires additional functional characterization of candidate genes via genetic manipulation and biochemical approaches, so that the desirable traits can be combined to produce superior strains (Hasan et al., 2011). In this study, a chitinase from $V$. lecanii was isolated and biochemically characterized and in vitro activities toward several phytopathogenic fungi were tested. Subsequently, a chitinase gene, VICHI, was cloned and analyzed to improve the desirable traits of $V$. lecanii through genetic engineering.

\section{MATERIAL AND METHODS}

\section{Organisms and culture conditions}

Verticillium lecanii strain CA-12 employed in this study was originally isolated from a dead whitefly Trialeurodes vaporariorum in Changchun urban, Jilin Province, China $\left(43^{\circ} 88^{\prime} \mathrm{N}\right.$, $125^{\circ} 35^{\prime} \mathrm{E}$ ) (Yu et al., 2012). A single-spore isolate of $V$. lecanii CA-12 was stored and cultures were grown on freshly prepared potato dextrose agar (PDA) plates at $25^{\circ} \mathrm{C}$. Escherichia coli DH5 $\alpha$ was used for DNA manipulation. The plasmid pMD18-T was purchased from Takara Co. (Shiga, Japan). For enzyme inducible production, the fungus was grown in 500-mL flasks containing $250 \mathrm{~mL}$ synthetic medium (SMCS) with chitosan and sucrose as carbon sources. SMCS was composed of (mg/L): $\mathrm{KH}_{2} \mathrm{PO}_{4}, 680 ; \mathrm{K}_{2} \mathrm{HPO}_{4}, 870 ; \mathrm{KCl}, 200 ; \mathrm{NH}_{4} \mathrm{NO}_{3}, 1000$; $\mathrm{CaCl}_{2}, 200 ; \mathrm{MgSO}_{4} \cdot 7 \mathrm{H}_{2} \mathrm{O}, 200 ; \mathrm{FeSO}_{4}, 2 ; \mathrm{ZnSO}_{4}, 2 ; \mathrm{MnSO}_{4}, 2$; as well as $5 \mathrm{~g}$ chitosan and 5 $\mathrm{g}$ sucrose; the $\mathrm{pH}$ of the medium was adjusted to 6.0 (Li et al., 2004).

\section{Assay of enzymatic activity}

Chitinolytic activity was determined using a colorimetric assay (Boller et al., 1983) with colloidal chitin as a substrate. The procedures were generally adapted from $\mathrm{Li}$ et al. (2004). One unit chitinase activity was defined as the amount of enzyme that catalyzed the release of $1 \mu \mathrm{M} \beta-1,4-N$-acetyl-D-glucosamine $/$ min at $40^{\circ} \mathrm{C}$.

\section{Enzyme production and purification}

For the production of chitinase, a fresh aliquot of $100 \mu \mathrm{L}$ strain $V$. lecanii CA-12 
conidial suspension $\left(1 \times 10^{7}\right.$ conidia $\left./ \mathrm{mL}\right)$ was inoculated into SMCS medium while shaking (200 rpm) at $25^{\circ} \mathrm{C}$. Cultivation of $V$. lecanii CA-12 for monitoring the chitinase production was carried out in SMCS medium. An enzyme assay to monitor the production of chitinase was carried out using the crude enzyme as the source of chitinase and swollen chitin as the substrate. The optimum time for maximum production of chitinase was monitored every $12 \mathrm{~h}$. Large-scale production of chitinase was carried out by mass fermentation, and the mycelia of the cultures after incubation were filtered and centrifuged at $10,000 \mathrm{~g}$ for $30 \mathrm{~min}$ at $4^{\circ} \mathrm{C}$. The resulting supernatant was used as the crude enzyme solution. All stages of purification were carried out at $4^{\circ} \mathrm{C}$. The following buffers were used: buffer A, $50 \mathrm{mM} \mathrm{HAc}-\mathrm{NaAc}, 1 \mathrm{mM}$ ethylenediaminetetraacetic acid (EDTA), and $1 \mathrm{mM}$ phenylmethylsulfonyl fluoride (PMSF) (pH 6.0); buffer B, $50 \mathrm{mM}$ Tris-HCl, $1 \mathrm{mM}$ EDTA, and $1 \mathrm{mM} \mathrm{PMSF}$ (pH 8.0).

\section{Fractional ammonium sulfate precipitation}

Salting out of the enzyme preparation was carried out in the first fractionation stage to $35 \%$ ammonium sulfate saturation and in the second to $90 \%$ saturation. After standing incubation for $12 \mathrm{~h}$, the resulting precipitate was collected by centrifugation at $12,000 \mathrm{~g}$ for $30 \mathrm{~min}$, dissolved in buffer A, and dialyzed overnight against 3 changes of $50 \mathrm{mM}$ phosphate buffer, $\mathrm{pH}$ 6.0. Insoluble material was removed by centrifugation at $10,000 \mathrm{~g}$ for $10 \mathrm{~min}$.

\section{Hydrophobic chromatography on phenyl-sepharose}

Solid ammonium sulfate was added to the dialyzed sample to $50 \%$ saturation, and then immediately loaded onto on a phenyl-sepharose column $(1 \times 20 \mathrm{~cm})$ equilibrated with buffer A including 50\% ammonium sulfate. After the column was washed with 5 column volumes of buffer $\mathrm{A}$, the proteins were eluted with a $100-\mathrm{mL}$ ammonium sulfate gradient solution (50-0\% saturation in buffer A at a flow rate of $1 \mathrm{~mL} / \mathrm{min})$. Fractions with chitinase activity were collected and dialyzed overnight against buffer A.

\section{Ion-exchange chromatography on DEAE-sepharose and CM-sepharose}

The dialyzed sample was passed over a DEAE-sepharose column $(1 \times 20 \mathrm{~cm})$ that had been pre-equilibrated with buffer A. First, the column was washed with 5 column volumes of buffer A, and then the enzymes were fractionated with a $240-\mathrm{mL}$ linear gradient of $0-0.3$ $\mathrm{M} \mathrm{NaCl}$ in buffer A at a flow rate of $1 \mathrm{~mL} / \mathrm{min}$. Fractions with chitinase activity were pooled and dialyzed overnight against buffer $\mathrm{B}$. The dialyzed sample was applied to a CM-sepharose column $(1.6 \times 20 \mathrm{~cm})$ that had been equilibrated with buffer B. After the column was washed with 5 column volumes of buffer B, chitinase was eluted with a $180-\mathrm{mL}$ linear gradient of $\mathrm{NaCl}(0-0.3 \mathrm{M}$ in buffer B) at a rate of $0.5 \mathrm{~mL} / \mathrm{min}$. Fractions with chitinase activity were pooled and concentrated to $2 \mathrm{~mL}$ using polyethylene glycol 6000 (PEG6000) according to the manufacturer instruction.

\section{Determination of protein content and chitinase molecular weight}

Protein concentrations were determined using the Bradford method (Bradford, 1976) with bovine serum albumin as the standard. The molecular weight of chitinase was determined 
by sodium dodecyl sulfate-polyacrylamide gel electrophoresis with a $10 \%(\mathrm{w} / \mathrm{v})$ isolation gel and 5\% (w/v) concentration gel according to the method of Laemmli (Laemmli, 1970). Gels were stained with Coomassie blue for protein visualization.

\section{Characterization of chitinase}

To determine the optimal temperature of enzyme chitinolytic activity, purified chitinase was incubated with colloidal chitin and examined for HAc-NaAc $(\mathrm{pH} 6.0)$ for $1 \mathrm{~h}$ at various temperatures $\left(20^{\circ}-80^{\circ} \mathrm{C}\right)$. In addition, the thermal stability of the enzyme was measured in terms of residual activity after incubation of purified chitinase at various temperatures ranging from $40^{\circ}-70^{\circ} \mathrm{C}$ in $50 \mathrm{mM}$ Tris- $\mathrm{HCl}, \mathrm{pH} 6.0$, for $30 \mathrm{~min}$. The $\mathrm{pH}$ activity profile of chitinase was also determined by measuring enzyme activity at $37^{\circ} \mathrm{C}$ for $1 \mathrm{~h}$ under standard conditions over a $\mathrm{pH}$ range of 3.0-8.0, $100 \mathrm{mM} \mathrm{CH}_{3} \mathrm{COOH}-\mathrm{CH}_{3} \mathrm{COONa}(\mathrm{pH} 3-6.5)$, and $100 \mathrm{mM}$ Tris$\mathrm{HCl}(\mathrm{pH} 7.0-8.0)$. The effects of metal ions (50 $\mathrm{mM}$ of $\mathrm{NaCl}, \mathrm{KCl}, \mathrm{CaCl}_{2}, \mathrm{MgCl}_{2}$, and $\mathrm{CuSO}_{4}$ ) on enzyme activity were investigated by pre-incubating the enzyme with colloidal chitin and $0.05 \mathrm{M}$ HAc-NaAc, $\mathrm{pH}$ 6.0, as well as different metal ions for $1 \mathrm{~h}$ at $40^{\circ} \mathrm{C}$. All experiments were performed in triplicate.

\section{Antifungal activity of purified enzyme in vitro}

Antifungal activity of the purified enzymes in vitro was determined using the method described by $\mathrm{Yu}$ et al. (2012) with slight modifications. Several agronomically important phytopathogens, including Penicillum italicum, F. moniliforme, Magnaporthe oryzae, and Setosphaeria turcica were selected and propagated on a PDA Petri dish at $28^{\circ} \mathrm{C}$ for 8 days. After sporulation, spores were collected, washed 3 times with $0.05 \mathrm{M}$ Tris- $\mathrm{HCl}$ buffer, $(\mathrm{pH}$ 8.0 ), and resuspended in $0.1 \%(\mathrm{~m} / \mathrm{v})$ glucose (approximately $1 \times 10^{8}$ spores $/ \mathrm{mL}$ ). Spores were utilized directly to examine the effects of chitinase on spore germination. Briefly, $5 \mu \mathrm{L}$ conidial suspensions and $5 \mu \mathrm{L}$ PD solution were mixed with $50 \mu \mathrm{L}$ purified chitinase at different concentrations in the wells of sterile depression slides, and incubated at $28^{\circ} \mathrm{C}$ for $24 \mathrm{~h}$. The control slides contained buffer B in place of enzyme solution. The results were recorded by light microscopy (Olympus BHS313, Tokyo, Japan), and the percentage of spore germination (100 randomly selected conidia) was determined and compared with that of the control.

\section{$V I C H I$ gene cloning and sequence analysis}

Verticillium lecanii strain CA-12 was used for cloning of VlCHI ( $V$. lecanii chitinase) in this study. Mycelia of $V$. lecanii were harvested and ground to fine powders in liquid nitrogen with a mortar and pestle. Genomic DNA (gDNA) was extracted using a cetyltrimethylammonium bromide (CTAB) method, while total RNA was prepared using TRIzol Reagent following the manufacturer instructions (Ambion, Austin, TX, USA). cDNA was synthesized using the PrimeScript ${ }^{\mathrm{TM}}$ RT reagent Kit with gDNA Eraser (Perfect Real Time) (Takara). The degenerate primers were: forward: 5'-TCCCCCGGGATGTTGAGYCTACTCAAAAARTCG

ATG-3', and reverse: 5'-GCTCTAGACTATTTCAT GCCATTCTTGATGTTG-3', and were designed according to the conserved region of the aligned amino acid and nucleotide sequences deduced from chitinase gene sequences in Cordyceps confragosa (GenBank Accession No. ABD77095), Trichoderma longibrachiatum (GenBank Accession No. ACZ63268), Hypocrea 
rufa (GenBank Accession No. AAF19618), Laganum attenuatum (GenBank Accession No. AGS15320), Trichoderma hamatum (GenBank Accession No. AAC60385), and L. psalliotae (GenBank Accession No. ABQ57240). A conventional polymerase chain reaction (PCR) amplification with high-fidelity $P f u$ DNA polymerase (Fermentas, Vilnius, Lithuania) was performed in a Bio-Rad S1000 ${ }^{\mathrm{TM}}$ Thermal Cycler (Hercules, CA, USA). The PCR product was recovered and ligated into the pMD18-T vector (Takara), which was then transformed into competent cells of $E$. coli DH5 $\alpha$. Positive E. coli clones were characterized by PCR, and 3 positive clones were individually sequenced by Invitrogen (Carlsbad, CA, USA). The sequence was subjected to a homology search in the NBCI database using the BLASTx program (http://blast.ncbi.nlm.nih.gov/ Blast.cgi). For phylogenetic analysis, amino acid sequences of chitinase were selected from GenBank and aligned using the ClustalX software (version 1.83). A phylogenetic tree was constructed using the MEGA software (version 4.0.2), and the neighbor-joining method using 1000 bootstrap replicates was used to ascertain the reliability of a given branch pattern in the neighbor-joining tree. In addition, the conserved domain of chitinase in parasitic fungi was aligned using the ClustalX software and analyzed using the BoxShade server (http://ch.embnet.org/software/BOX_form. $\mathrm{html}$ ). The 3-dimensional (3D) structure of VlCHI was predicted by protein modeling with the SWISS-MODEL server (http://swissmodel.expasy.org/), using a chitinase template of Bionectria ochroleuca chitinase (GenBank Accession No. EU000575.1; PDB code 3G6M).

\section{RESULTS}

\section{Kinetics of enzyme production by $\boldsymbol{V}$. lecanii}

The production of extracellular chitinase from $V$. lecanii grown in liquid SMCS culture supplemented with chitosan for inducible production was determined at different growth phases. Extracellular chitinase activity was detected after $24 \mathrm{~h}$ in the culture supernatants and levels of chitinase activity increased after $48 \mathrm{~h}$ of incubation, after which expression decreased (Figure 1). Thus, $48 \mathrm{~h}$ was selected as the fermentation time course for large-scale production of chitinase.

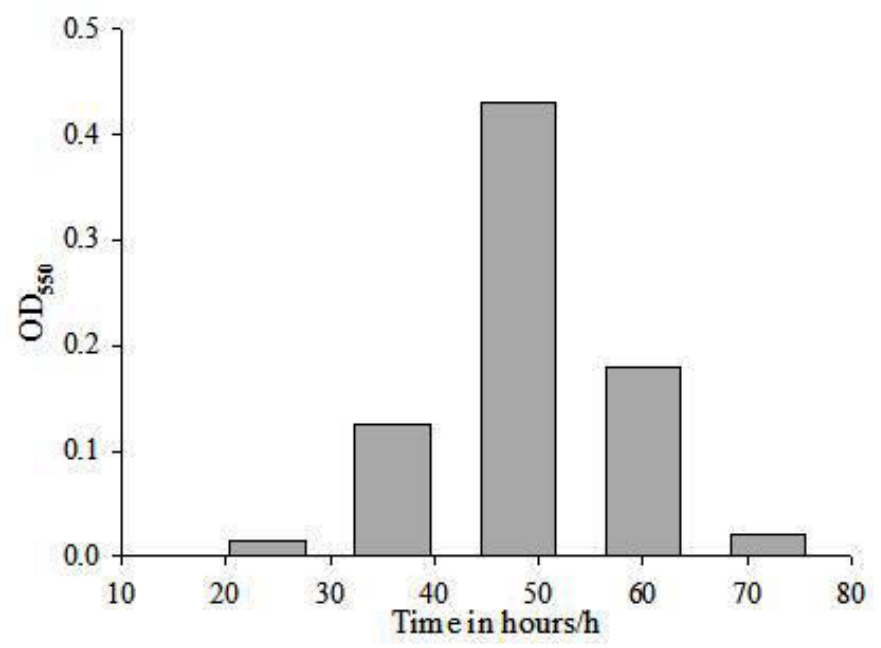

Figure 1. Chitinase production at different incubation periods (hours) in Verticillium lecanii CA12. 


\section{Purification of chitinase from $V$. lecanii}

Fractions of the chitinase peak on the DEAE-sepharose fast flow column were collected and dialyzed overnight at $4^{\circ} \mathrm{C}$ against $50 \mathrm{mM}$ Tris- $\mathrm{HCl}$ containing $1 \mathrm{mM}$ EDTA and 1 mM PMSF, $\mathrm{pH}$ 8.0; EDTA and PMSF were included to inhibit protease activity. The enzyme was then applied to a CM-sepharose ion-exchange column for chromatography. The chitinase activity peak fraction was collected and run on a sodium dodecyl sulfate-polyacrylamide gel. The chitinase was purified 18.76-fold with a final yield of $16.9 \%$ and specific activity of 29.26 $\mathrm{U} / \mathrm{mg}$. The purification procedures of extracellular chitinase secreted by $V$. lecanii CA12 are summarized in Table 1. Enzyme purity and molecular mass were determined by gel electrophoresis, showing a single polypeptide chain of approximately $42.0 \mathrm{kDa}$ (Figure 2).

Table 1. Purification of extracellular chitinase from Verticillium lecanii CA12.
\begin{tabular}{lcccccc}
\hline Purification step & Volume (mL) & Total protein (mg) & Specific activity (U/mg) & Total activity (U) & Yield (\%) & Purification (fold) \\
\hline Crude extract & 900 & 837.43 & 1.56 & 1306.7 & 100 & 1.00 \\
$90 \%\left(\mathrm{NH}_{4}\right)_{2} \mathrm{SO}_{4}$ & 26 & 113.18 & 3.91 & 442.3 & 33.8 & 2.51 \\
Phenyl-Sepharose & 23 & 44.77 & 8.24 & 369.1 & 28.2 & 5.28 \\
DEAE-Sepharose & 18 & 17.07 & 16.8 & 286.7 & 21.9 & 10.76 \\
CM-Sepharose & 15 & 7.54 & 29.26 & 220.6 & 16.9 & 18.76 \\
\hline
\end{tabular}

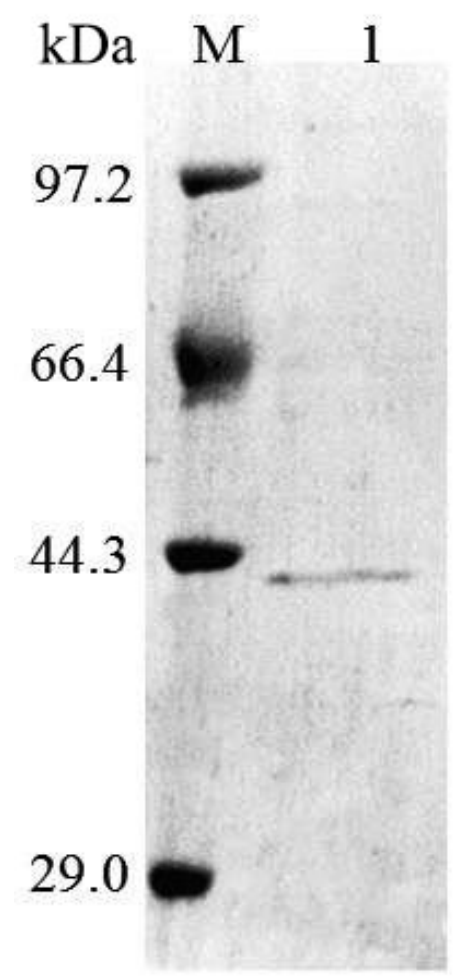

Figure 2. SDS-PAGE of purified chitinase from Verticillium lecanii strain CA12. Lane $M=$ standard protein molecular weight marker; lane 1 = protein samples from CM-sepharose $(0.8 \mu \mathrm{g}$ protein was loaded onto the gel $)$. 


\section{Characterization of chitinase}

To determine the optimum temperature of purified chitinase activity, enzyme reactions were performed over a range of temperatures from $20^{\circ}$ to $80^{\circ} \mathrm{C}$ in $\mathrm{HAc}-\mathrm{NaAc}, \mathrm{pH}$ 6.0, for $1 \mathrm{~h}$, using colloidal chitin as substrate. Optimum enzyme activity was observed at $40^{\circ} \mathrm{C}$. When the reaction temperature reached higher than $50^{\circ} \mathrm{C}$, there was a sharp decrease in activity, with only $33 \%$ of the maximum activity observed at $80^{\circ} \mathrm{C}$ (Figure $3 \mathrm{~A}$ ). Regarding the thermostability of purified chitinase, only $23 \%$ activity was retained after $60 \mathrm{~min}$ at $50^{\circ} \mathrm{C}$, whereas complete inactivation was observed when the enzyme was incubated at $60^{\circ} \mathrm{C}$ for $50 \mathrm{~min}$ and $70^{\circ} \mathrm{C}$ for $40 \mathrm{~min}$ (Figure 3B). Experiments examining the influence of $\mathrm{pH}$ on enzyme activity were also carried out. Residual relative activity of more than $70 \%$ was found in the $\mathrm{pH}$ range of 4.0-5.0, with optimum activity at $\mathrm{pH} 4.6$ (Figure 3C), indicating that the purified chitinase was acidic. Enzyme activity was measured in the presence of different metal ions by incubating the enzymes with colloidal chitin and $50 \mathrm{mM} \mathrm{HAc-NaAc}, \mathrm{pH} 4.8$, including different metal ions such as $\mathrm{Ca}^{2+}, \mathrm{Cu}^{2+}, \mathrm{Mg}^{2+}, \mathrm{K}^{+}$, and $\mathrm{Na}^{+}$for $1 \mathrm{~h}$ at $40^{\circ} \mathrm{C}$. Activity without metal ions was estimated to be $100 \%$. Chitinase activity was strongly activated by $50 \mathrm{mM} \mathrm{Mg}^{2+}$, and partially by $\mathrm{Ca}^{2+}$ (Table 2 ), whereas chitinase activity was slightly affected by $\mathrm{Cu}^{2+}, \mathrm{K}^{+}$, and $\mathrm{Na}^{+}$.

$\mathbf{A}$
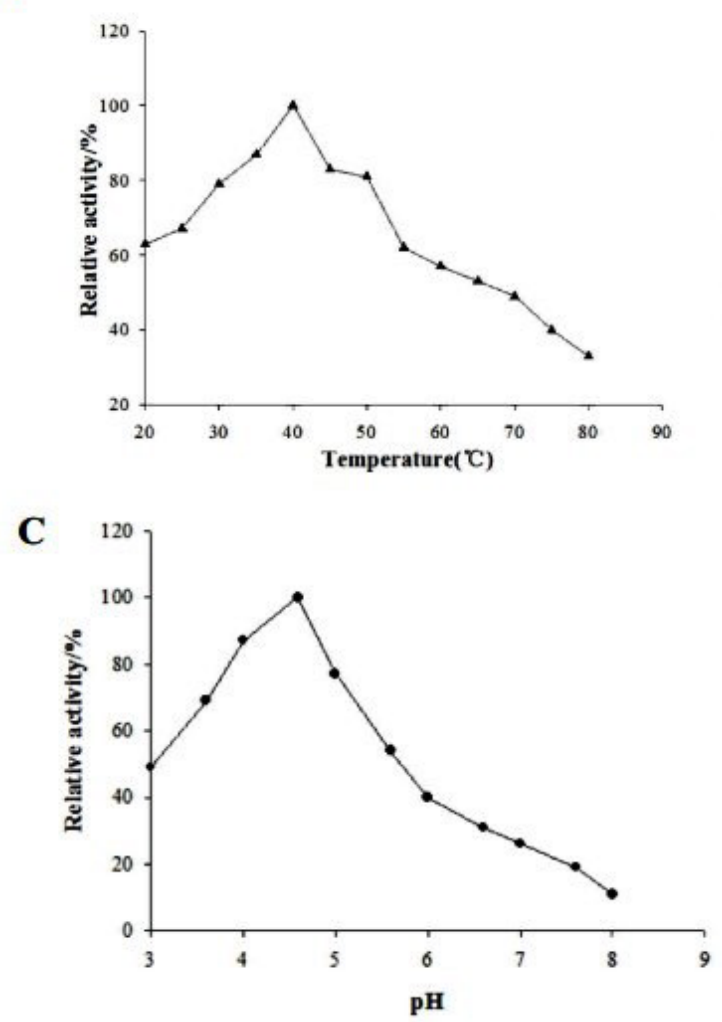

B

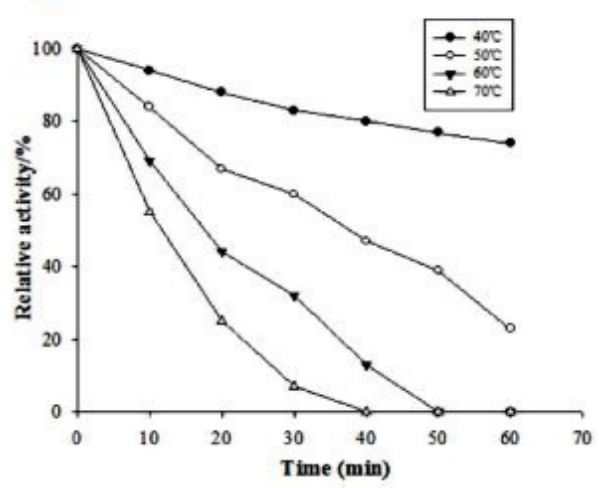

Figure 3. Activity and stability of purified chitinase. A. Optimum reaction temperature of purified chitinase. B. Stability of purified chitinase at different temperatures. C. Activity of purified chitinase at different $\mathrm{pH}$ values. 
Table 2. Effect of various metal ions on the activity of chitinase V1CHI.

\begin{tabular}{lcc}
\hline Metal ions & Concentration $(\mathrm{mM})$ & Relative activity $(\%)$ \\
\hline Control & 0 & 100 \\
$\mathrm{Na}^{+}$ & 50 & 63 \\
$\mathrm{~K}^{+}$ & 50 & 55 \\
$\mathrm{Ca}^{2+}$ & 50 & 108 \\
$\mathrm{Mg}^{2+}$ & 50 & 208 \\
$\mathrm{Cu}^{2+}$ & 50 & 78 \\
\hline
\end{tabular}

\section{Effect of chitinase on phytopathogenic fungi}

Antifungal activity was determined using isolated chitinase at different concentrations. Spore germination of the different phytopathogenic fungi tested was inhibited by different concentrations of chitinase. Partially purified chitinase exhibited prominent antifungal activity against the phytopathogenic fungus $F$. moniliforme, followed by P. italicum. This fungus was inhibited by more than $90 \%$ under the conditions used in this study at a concentration of $300 \mu \mathrm{g} / \mathrm{mL}$ (Figure 4).

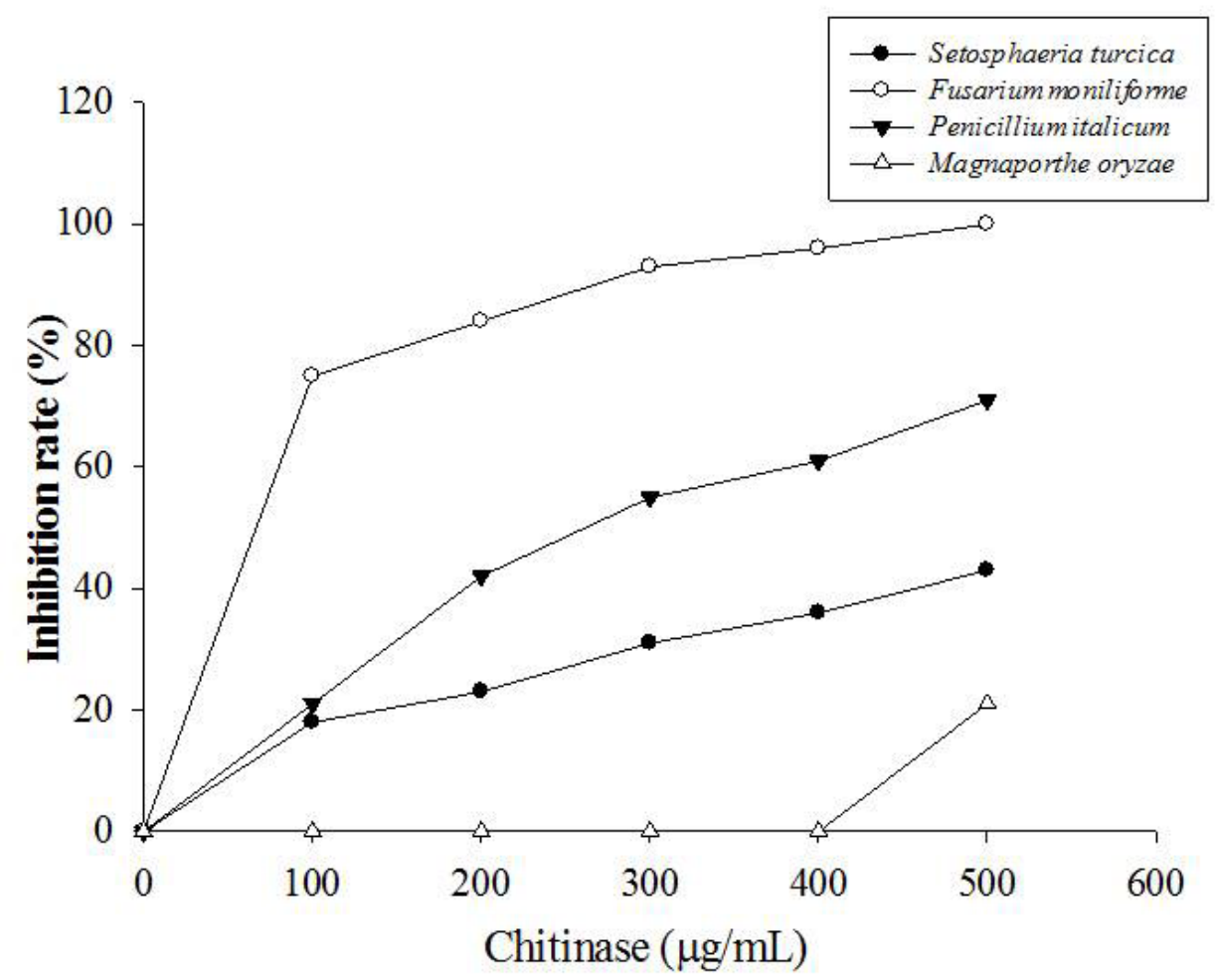

Figure 4. In vitro antifungal activity (\%) of purified chitinase (V1CHI) from 0 to $500 \mu \mathrm{g} / \mathrm{cm}^{3}$. Approximately 1000 fungal spores were cultured in the agar plate with or without different amounts of chitinase at $25^{\circ} \mathrm{C}$ for $10 \mathrm{~h}$. Inhibition of spore germination was examined under a light microscope. 


\section{Cloning and sequence analysis of $\mathrm{VICHI}$ gene}

Using $V$. lecanii total cDNA and gDNA as templates, the full-length cDNA open reading frame was generated via reverse transcription-PCR. The fragment was $1272 \mathrm{bp}$, indicating that $\mathrm{VlCHI}$ is composed of 423 amino acids with a predicted molecular weight (MW) of $45.8 \mathrm{kDa}$; the $\mathrm{pI}$ of mature chitinase protein was predicted to be 5.67 , which is consistent with the optimum $\mathrm{pH}$ for the enzyme purified in this study. In addition, the genomic DNA sequence of chitinase was also determined. The gene-coding sequence of the genomic DNA spanned $1432 \mathrm{bp}$ and contained 3 introns of 57, 51, and $52 \mathrm{bp}$, respectively (Figure 5). Many extracellular chitinase molecules are translated with a signal sequence, followed by a cleavage into a mature protein. The signal P4.1 server (http://www.cbs.dtu. $\mathrm{dk} /$ services/SignalP/) analysis, which is used to predict the presence of signal peptides in protein sequences and the location of potential cleavage sites, predicted that VlCHI contained a putative signal peptide of 20 amino acids (MLSLLKKSMAVAVALQAVTA) for excreted proteins, and the MW of the predicted mature chitinase matched the size of the purified enzyme in this study. The $V l C H I$ cDNA and gDNA sequences were deposited in GenBank (accessions numbers are KF041476 for gDNA and KF041477 for cDNA). A GenBank database search showed that the nucleotide and amino acid sequence of VlCHI had extensive similarities with members of the Family 18 chitinases, and the chitinase from V. lecanii obtained in this study can be assigned to the GH18 (glycosyl hydrolases, Family 18) type II chitinases. The sequences of its homolog in parasitic fungi were aligned using the ClustalX program. Chitinases in fungi were found to be conserved. V1CHI contained the conserved substrate-binding and catalytic domains (SXGG and DXXDXDXE) of glycosyl hydrolase Family 18 (Yang et al., 2010), and a conserved catalytic triad center containing Asp169, Trp170, and Glu171, which are very important for chitin binding and catalytic activity (Figure 6). Chitinase VlCHI showed overall sequence similarities ranging from 70 to $90 \%$ to 4 other chitinases (LfChi, ThChi, MaChi, and BoChi), and with $91 \%$ similarity to a basic chitinase chi2 from V. lecanii strain DAOM 175104 (Lu et al., 2005). However, the amino acid residues around the substrate-binding site and the catalytic center were very conserved (Figure 6). The 3-D structure of VICHI was modeled using the SWISS-MODEL server employing the crystal structure of chitinase from B. ochroleuca chitinase (GenBank No. EU000575.1; PDB code 3G6M) as a template, which is highly homologous to V. lecanii chitinase, and whose crystal structure was previously reported (Yang et al., 2010). The predicted 3-D structure revealed that 8 strands of parallel $\beta$ barrels were surrounded by $8 \alpha$-helices to form the core domain, named the $(\beta / \alpha) 8$ triosephosphate isomerase barrel, which is common in other Family 18 chitinases (Yang et al., 2010), and the N-terminal catalytic domain contained 3 putative active residues facing each other (Figure 7).

\section{DISCUSSION}

Biological control agents may effectively overcome most of the challenges related to extensive use of pesticides, and subsequently, they have gained worldwide attention in recent studies of sustainable crop products and protection. There are currently 2 main research fields in biological control, including searching for highly efficient strains and screening of compounds or proteins with activity toward desired targets. More recently, researchers have 


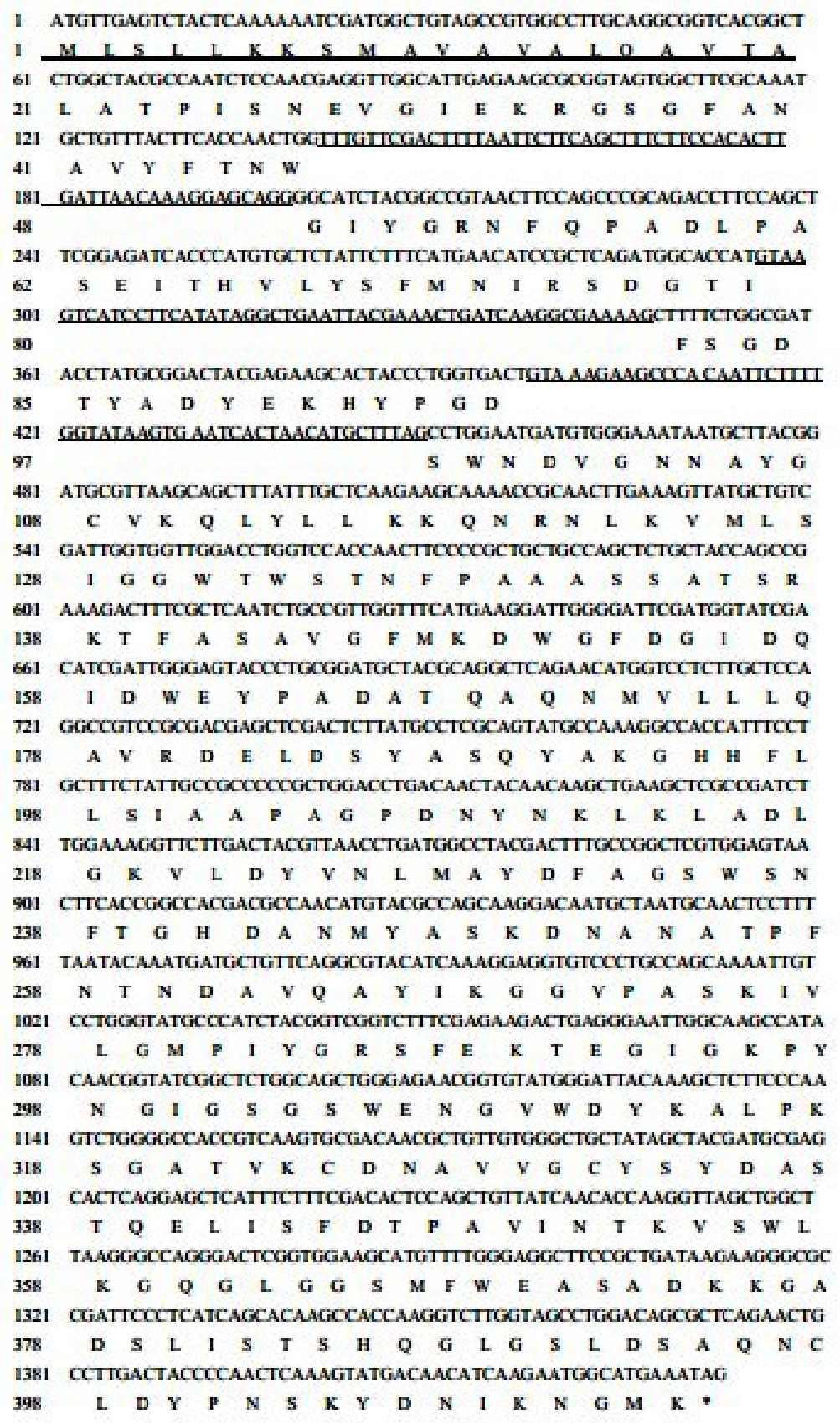

Figure 5. Nucleotide and deduced amino acid sequence of chitinase gene VlCHI (GenBank accession No. KF041476). The nucleotide and/or amino acid sequence is numbered on the left. The upper lines show the nucleotide sequence with 3 introns (single-line underlined). The putative signal peptide is double-underlined. The stop codon is indicated with an asterisk $(*)$. 
B.ochroleuca:
T. harrianon:
L. fungicola:
V.lecanii:
M. anisopliae:
B.ochroleuca:
T. harzianon:
L. fungicola:
V. lecanii:
M. anisopliae:

B.ocholenca:

T. harzianzon:

L. fungicola:

V. lecanii:

M. anisopliae:

B.ocholousa:

T. harzianoon:

L. fungicola:

V. lecanii:

M. anisopliae:

B.ocholenca:

T. harziannon:

L. fungicola:

V. lecanii:

$M$ anisoplias:

B.ocholeuca:

T. harzianzon:

L. fungicola:

V. lecanii:

M. anisopliae:

B.ocholeuca:

T. harziandon:

L. fungicola:

V. lecanii:

M. anisopliae:

B.ocholenca:

T. harzianzon:

L. fungicola:

V. lecanii:

M. anisopliae:

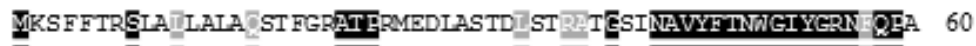

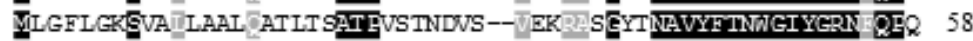

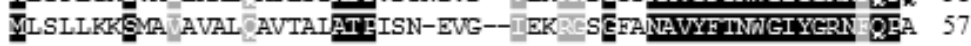

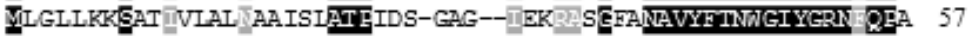

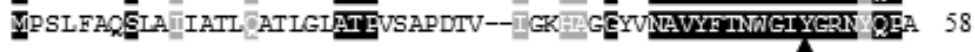

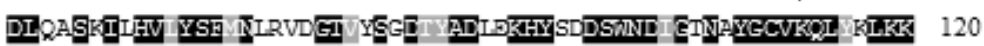

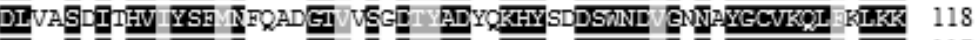

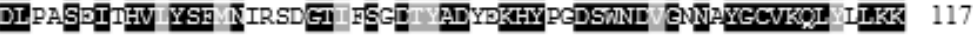

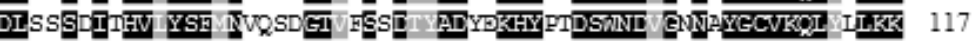

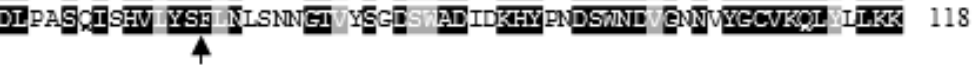

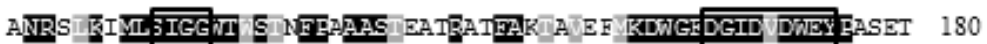

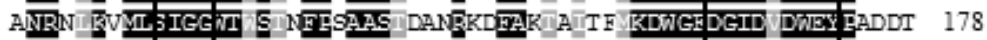

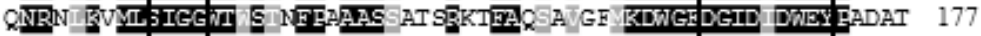

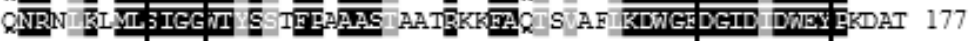

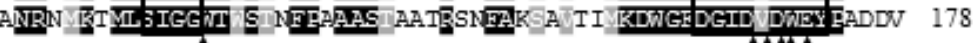
4 Trim

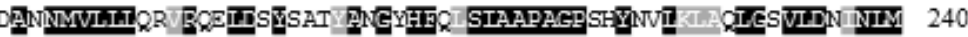

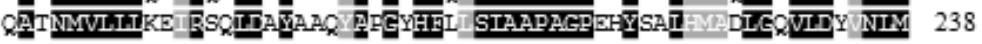

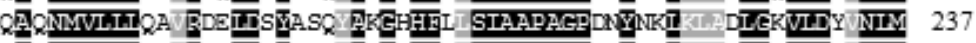

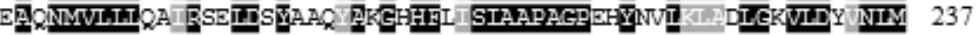

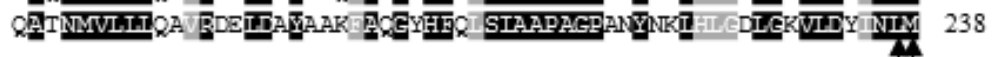

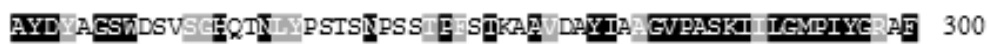

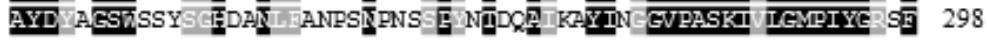

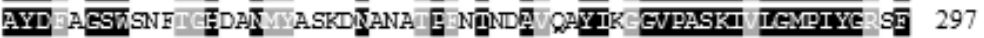

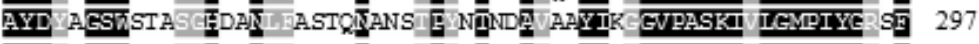

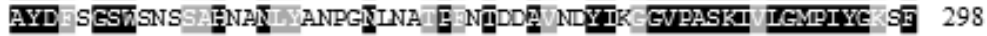
44

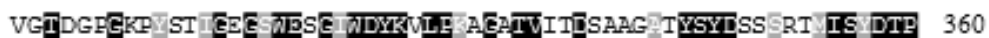

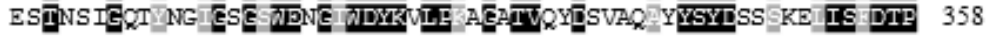

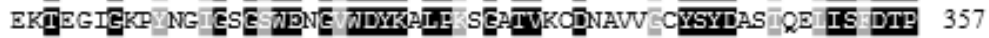

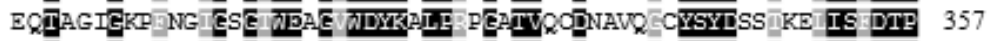

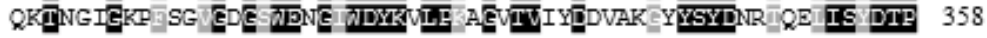

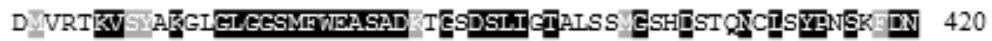

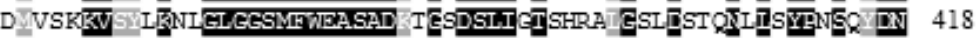

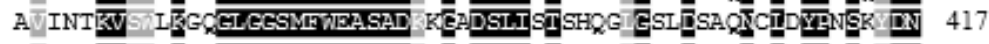

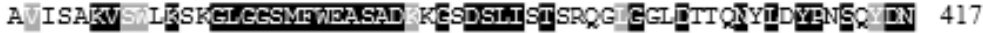

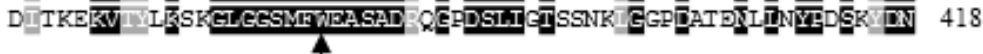
IINSIIS 426
IRSGN 424
IING $\quad 423$
IIKG $K$ N 423
YTRQ $\mathrm{KQ}$ A 424

Figure 6. Multiple sequence alignment of V1CHI homologs. The proteins shown are chitinase from Verticillium lecanii (KF041477.1), Lecanicillium fungicola (AAP45631.1), Metarhizum anisopliae (AAY32603.1), and Trichoderma harzianum (ABD42923.1), as well as chitinase from Bionectria ochroleuca (EU000575.1). A black background indicates conserved residues; a brown background indicates residues identified to be more than $80 \%$ conserved. The conserved substrate-binding and catalytic domains (SXGG and DXXDXDXE) are marked with a black frame, and the key residues (Asp, Trp, Glu) important for chitin binding are marked with asterisks $(*)$. The key residues in the active site are indicated with short black arrows. 

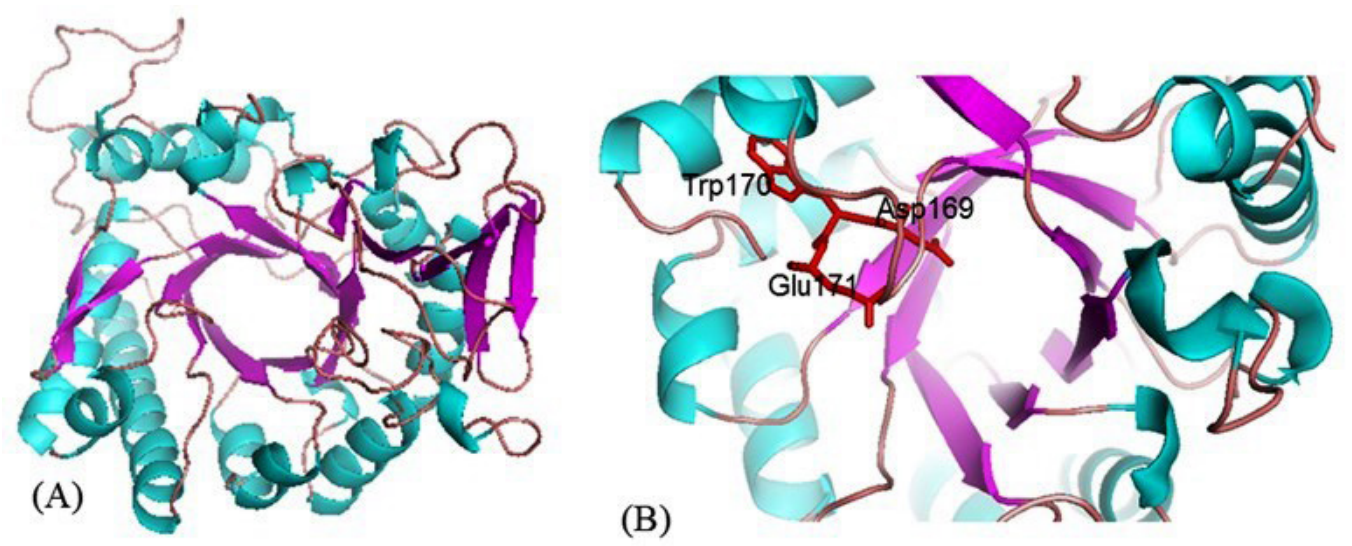

Figure 7. Overall hypothetical 3-dimensional structures of VlCHI. A. The structure was generated based on homology modeling using chitinase from Bionectria ochroleuca chitinase GenBank (GenBank No. EU000575.1; PDB code $3 \mathrm{G} 6 \mathrm{M})$ as a template. Helices, strands, and coil are colored cyan, purple, and violet, respectively. B. Putative active sites in the catalytic domain of VlCHI.

exploited molecular manipulation to generate genetically modified microorganisms combined with different bio-control traits. Wu et al. (2013) generated a transgenic Streptomyces lydicus by transforming an exogenous resistance gene, a chit42 gene from T. harzianum, which not only enhanced antibiotic production but also highly improved the activity of pathogen cell wall degradation, particularly against $B$. cinerea. Li et al. (2012) constructed a transgenic Trichoderma koningi containing a Metarhizium anisopliae chit42 gene, which significantly increased its activity towards the Asian corn borer. Xia et al. (2009) expressed a subtilisinlike protease, CDEP, from Beauveria bassiana that was co-fused with the Cry1Ac protein in Bacillus thuringiensis and showed that it could improve insecticidal activity toward Helicoverpa armigera larvae. V. lecanii is a candidate organism used as a pest biological control agent against insects and phytopathogens (Benhamou and Brodeur, 2001; Yu et al., 2012). Isolating and characterizing candidate proteins and genes in $V$. lecanii, then testing their activity in vivo and in vitro is important, as the transformation system of $V$. lecanii has been established (Hasan et al., 2011).

In this study, we isolated an acidic extracellular chitinase from the entomopathogenic fungus $V$. lecanii using different columns for chromatography. The enzyme exhibited the highest activity at $40^{\circ} \mathrm{C}$ and $\mathrm{pH} 4.6$, and was significantly activated by $\mathrm{Mg}^{2+}$, while Lu et al. (2005) isolated a chitinase, whose optimum enzymatic activity was observed at $22^{\circ} \mathrm{C}$ and $\mathrm{pH} 7.5$. There are at least 2 chitinases in $V$. lecanii, an acidic and a basic chitinase. In plants, there are 2 classes of chitinases, basic or acidic chitinases, targeting different parts of the cell, and are differentially regulated. Acidic chitinases are secreted into the extracellular region, whereas basic chitinases generally accumulate intracellularly and are induced by stress-related environments ( $\mathrm{Lu}$ et al., 2005). Our results indicate that the acidic chitinases are highly expressed during in vitro culture of $V$. lecanii. In vitro antifungal assay experiments of $\mathrm{VlCHI}$ revealed spore germination inhibitory activity against several devastating fungal phytopathogens that extensively attack plants, particularly F. moniliforme, P. italicum, S. turcica, and M. oryza. Future experiments should be conducted to determine the efficacy of $\mathrm{VlCHI}$ against other fungi 
as well. Next, we cloned the correlative gene $V l C H I$ from this organism using degenerate primers. Sequence alignment showed that the chitinase examined in this study belonged to the GH18 superfamily and is conserved in parasitic fungi according to BLASTp results. In general, GH18 family chitinases bind their substrates in an extended recognition site, and VlCHI in this study contained the conserved substrate-binding and catalytic domains (SXGG and DXXDXDXE), as well as a conserved catalytic center containing 3 vital amino acid residues, Asp169, Trp170, and Glu171 (Yang et al., 2010). Several structures of fungal chitinase have been determined, such as chitinase from Aspergillus fumigatus (AfCHI) (PDB code: 1W9P) (Rao et al., 2005), Coccidioides immitis (cmChi) (PDB code: 1D2K) (Hollis et al., 2000), Yersinia entomophaga (YeCHI) (PDB code: 4A5Q) (Busby et al., 2012), and B. ochroleuca (also known as Clonostachys rosea) (BoChi1) (PDB code: 3G6M), and these structure were used to predict chitin binding, while biochemical assays were used to characterize chitinase in fungi. In this study, we utilized B. ochroleuca (BoChi1) (PDB code: 3G6M) as a template to generate a 3-D protein model of VICHI using the SWISS-MODEL server. Protein modeling and structural comparison of different chitinases validated the conserved active sites (Figures 6 and 7).

In summary, we isolated an acidic chitinase $\mathrm{VlCHI}$ in $V$. lecanii during in vitro culture when chitosan was added as a substrate and tested the optimum $\mathrm{pH}$ and temperature for its activity. In addition, $\mathrm{VlCHI}$ exhibited inhibitory activity toward several agronomically important phytopathogens, specifically $F$. moniliforme, and few previous studies showed that proteins in $V$. lecanii exhibited activity against phytopathogens (Yu et al., 2012). The cDNA sequence was obtained and analyzed, and the putative amino acids shared extensive similarities with other parasitic fungal chitinases, indicating that chitinase is well-conserved in parasitic fungi. However, the relationship between different amino acid residues in chitinase from different microorganisms and the parasitic specificity should be investigated for the generation of improved biocontrol strains. Our study provides insight for modifying recombinant biocontrol strains used in an acidic environment, as well as toward some plant pathogens.

\section{ACKNOWLEDGMENTS}

Research supported by the Twelfth Five Year Plan Project of Science and Technology Support, China (\#2014BAD14B02 to P.H., \#2013BAC09B01 to Z.H., \#2012BAD19B04 to P.H.), by the Research and Development of Industrial Technology Special at Jilin Provincial Development and Reform Commission (\#2013C001 to P.H), and by the Ministry of Agriculture Key Project of GM Cultivation of New Varieties (\#2013ZX08004004 to L.Q.), China.

\section{REFERENCES}

Benhamou N and Brodeur J (2000). Evidence for antibiosis and induced host defense reactions in the interaction between Verticillium lecanii and Penicillium digitatum, the causal agent of green mold. Phytopathology 90: 932-943.

Benhamou N and Brodeur J (2001). Pre-inoculation of Ri T-DNA transformed cucumber roots with the mycoparasite, Verticillium lecanii, induces host defense reactions against Pythium ultimum infection. Physiol. Mol. Plant Pathol. 58: 133-146.

Boller T, Gehri A, Mauch F and Vögeli U (1983). Chitinase in bean leaves: induction by ethylene, purification, properties, and possible function. Planta 157: 22-31.

Bradford MM (1976). A rapid and sensitive method for the quantitation of microgram quantities of protein utilizing the principle of protein-dye binding. Anal. Biochem. 72: 248-254.

Busby JN, Landsberg MJ, Simpson RM, Jones SA, et al. (2012). Structural analysis of Chi1 chitinase from Yen-Tc: the 
multisubunit insecticidal ABC toxin complex of Yersinia entomophaga. J. Mol. Biol. 415: 359-371.

Gan Z, Yang J, Tao N, Liang L, et al. (2007). Cloning of the gene Lecanicillium psalliotae chitinase Lpchil and identification of its potential role in the biocontrol of root-knot nematode Meloidogyne incognita. Appl. Microbiol. Biotechnol. 76: 1309-1317.

Hammami I, Siala R, Jridi M, Ktari N, et al. (2013). Partial purification and characterization of chilO8, a novel antifungal chitinase produced by Bacillus cereus IO8. J. Appl. Microbiol. 115: 358-366.

Harman GE, Hayes CK, Lorito M, Broadway RM, et al. (1993). Chitinolytic enzymes of Trichoderma harzianum: purification of chitobiosidase and endochitinase. Phytopathology 83: 313-318.

Hasan S, Singh RI and Singh SS (2011). Development of transformation system of Verticillium lecanii (Lecanicillium spp.) (Deuteromycotina: Hyphomycetes) based on nitrate reductase gene of Aspergillus nidulans. Indian J. Microbiol. 51: 390-395.

Henrissat B and Bairoch A (1993). New families in the classification of glycosyl hydrolases based on amino acid sequence similarities. Biochem. J. 293: 781-788.

Hollis T, Monzingo AF, Bortone K, Ernst S, et al. (2000). The X-ray structure of a chitinase from the pathogenic fungus Coccidioides immitis. Protein Sci. 9: 544-551.

Ihrmark K, Asmail N, Ubhayasekera W, Melin P, et al. (2010). Comparative molecular evolution of Trichoderma chitinases in response to Mycoparasitic interactions. Evol. Bioinform. 6: 1-26.

Jankiewicz U, Brzezinska MS and Saks E (2012). Identification and characterization of a chitinase of Stenotrophomonas maltophilia, a bacterium that is antagonistic towards fungal phytopathogens. J. Biosci. Bioeng. 113: 30-35.

Laemmli UK (1970). Cleavage of structural proteins during the assembly of the head of bacteriophage T4. Nature 277: $680-685$.

Li DC (2006). Review of fungal chitinases. Mycopathologia 161: 345-360.

Li DC, Zhang SH, Liu KQ and Lu J (2004). Purification and partial characterization of a chitinase from the mycoparasitic fungus Trichothecium roseum. J. Gen. App. Microbiol. 50: 35-39.

Li YY, Tang J, Fu KH, Gao SG, et al. (2012). Construction of transgenic Trichoderma koningi with chit42 of Metarhizium anisopliae and analysis of its activity against the Asian corn borer. J. Environ. Sci. Health B 47: 622-630.

Liu T, Liu Z, Song C, Hu Y, et al. (2012). Chitin-induced dimerization activates a plant immune receptor. Science 336: 1160-1164.

Lu ZX, Laroche A and Huang HC (2005). Isolation and characterization of chitinases from Verticillium lecanii. Can. J. Microbiol. 51: 1045-1055.

Mi Q, Yang J, Ye F, Gan Z, et al. (2010). Cloning and overexpression of Pochonia chlamydosporia chitinase gene pcchi44, a potential virulence factor in infection against nematodes. Process Biochem. 45: 810-814.

Miller TC, Gubler WD, Laemmlen FF, Geng S, et al. (2004). Potential for using Lecanicillium lecanii for suppression of strawberry powdery mildew. Biocontrol Sci. Technol. 14: 215-220.

Prasanna L, Eijsink VH, Meadow R and Gåseidnes S (2013). A novel strain of Brevibacillus laterosporus produces chitinases that contribute to its biocontrol potential. Appl. Microbiol. Biotechnol. 97: 1601-1611.

Rao FV, Andersen OA, Vora KA, DeMartino JA, et al. (2005). Methylxanthine drugs are chitinase inhibitors: investigation of inhibition and binding modes. Chem. Biol. 12: 973-980.

Rocha-Pino Z, Vigueras G and Shirai K (2011). Production and activities of chitinases and hydrophobins from Lecanicillium lecanii. Bioproc. Biosyst. Eng. 34: 681-686.

Sahai AS and Manocha MS (1993). Chitinases of fungi and plants: their involvement in morphogenesis and host-parasite interaction. FEMS Microbiol. Rev. 11: 317-338.

Wu Q, Bai L, Liu W, Li Y, et al. (2013). Construction of a Streptomyces lydicus A01 transformant with a chit42 gene from Trichoderma harzianum $\mathrm{P} 1$ and evaluation of its biocontrol activity against Botrytis cinerea. J. Microbiol. 51: 166-173.

Xia L, Zeng Z, Ding X and Huang F (2009). The expression of a recombinant cry1Ac gene with subtilisin-like protease CDEP2 gene in a crystalliferous Bacillus thuringiensis by red/ET homologous recombination. Curr. Microbiol. 59: 386-392.

$\mathrm{Xu} \mathrm{X,} \mathrm{Yu} \mathrm{Y} \mathrm{and} \mathrm{Shi} \mathrm{Y} \mathrm{(2011).} \mathrm{Evaluation} \mathrm{of} \mathrm{inert} \mathrm{and} \mathrm{organic} \mathrm{carriers} \mathrm{for} \mathrm{Verticillium} \mathrm{lecanii} \mathrm{spore} \mathrm{production} \mathrm{in} \mathrm{solid-}$ state fermentation. Biotechnol. Lett. 33: 763-768.

Yang J, Gan Z, Lou Z, Tao N, et al. (2010). Crystal structure and mutagenesis analysis of chitinase CrChil from the nematophagous fungus Clonostachys rosea in complex with the inhibitor caffeine. Microbiology 156: 3566-3574.

Yu G, Liu JL, Xie LQ, Wang XL, et al. (2012). Characterization, cloning, and heterologous expression of a subtilisin-like serine protease gene VlPr1 from Verticillium lecanii. J. Microbiol. 50: 939-946. 